\title{
On some species of Apatetica WeSTWOOD (Coleoptera: Staphylinidae: Apateticinae)
}

\author{
With 43 figures
}

VOLKER ASSING ${ }^{1}$

${ }^{1}$ Gabelsbergerstraße 2, 30163 Hannover, Germany. - vassing.hann@t-online.de Published on 2018-12-06

DOI:10.21248/contrib.entomol.68.2.347-359

\begin{abstract}
Eight species of Apatetica WeSTwood, 1848 are (re-)described and illustrated, six of them for the first time: Apatetica viridipennis FauveL, 1895 (North India); A. glaucipennis spec. nov. (Nepal); A. confusa spec. nov. (Myanmar; previously confounded with A. viridipennis); A. aspera spec. nov. (China: Sichuan); A. laevicollis FAUveL, 1904 (Vietnam); A. glabra spec. nov. (China: Yunnan); A. gibba spec. nov. (China: Gansu); A. curtipennis spec. nov. (China: Yunnan). A lectotype is designated for Apatetica laevicollis. The first confirmed record of A. laevicollis since the original description is reported. The genus currently includes 25 described species distributed in the southern East Palaearctic and Oriental regions.
\end{abstract}

\section{Taxonomic acts}

Apatetica glaucipennis spec. nov. - urn:lsid:zoobank.org:act:42C008AA-4925-4FC9-AA0B-3F043FC50F97

Apatetica confusa spec. nov. - urn:lsid:zoobank.org:act:03A55D46-5010-43D8-BFEF-9D02E3BE2D1A

Apatetica aspera spec. nov. - urn:lsid:zoobank.org:act:221E2344-6290-429C-930E-32F970F7DD72

Apatetica glabra spec. nov. - urn:Isid:zoobank.org:act:01C0EC41-4144-4C16-812E-1A8A7507673C

Apatetica gibba spec. nov. - urn:lsid:zoobank.org:act:51D50FDD-A847-43CC-9760-A14D6BC90FE5

Apatetica curtipennis spec. nov. - urn:lsid:zoobank.org:act:B7194436-4CE7-4826-BBE6-C23559533C3E

\section{Key words}

Coleoptera, Staphylinidae, Apateticinae, Apatetica, East Palaearctic region, Oriental region, Nepal, China, Vietnam, taxonomy, descriptions, new species, lectotype designation, new record

\section{Zusammenfassung}

Acht Arten der Gattung Apatetica Westwood, 1848 werden beschrieben und abgebildet, sechs davon neu: Apatetica viridipennis Fauvel, 1895 (Nordindien); A. glaucipennis spec. nov. (Nepal); A. confusa spec. nov. (Myanmar; bisher mit A. viridipennis konfundiert); A. aspera spec. nov. (China: Sichuan); A. laevicollis Fauvel, 1904 (Vietnam); A. glabra spec. nov. (China: Yunnan); A. gibba spec. nov. (China: Gansu); A. curtipennis spec. nov. (China: Yunnan). Für Apatetica laevicollis wird ein Lektotypus designiert. Der erste bestätigte Nachweis von A. laevicollis seit der Originalbeschreibung wird gemeldet. Die Gattung enthält derzeit 25 Arten und ist in der südlichen Ostpaläarktis sowie in der Orientalis verbreitet. 


\section{Introduction}

The enigmatic genus Apatetica Westwood, 1848 previously included 19 valid species distributed in the southern East Palaearctic and Oriental regions from the Himalaya to Japan and the Sunda Islands (Herman 2001). Together with Nodynus Waterhouse, 1876, a genus containing only five species, it forms the small subfamily Apateticinae. A key to the Apatetica species recorded from India and adjacent regions was provided by CAMERon (1930). Next to nothing is known about the natural history of Apatetica species.

The present study was initiated by some material forwarded to me by Andreas Weigel (Wernburg). A subsequent examination of this material and of Apatetica collected by myself in China suggested that, based on the original descriptions of previously known species and on the key provided by CAMERon (1930), it included several undescribed species. Since the genus had not been revised previously, type material of the described species was loaned from the natural history museums in London, Brussels, and Stockholm. A study of this type material confirmed that, indeed, most of the species examined earlier were undescribed. The plan to revise at least all the species from Continental Asia, however, had to be reconsidered when it came to my attention that Harald Schillhammer (Vienna) was in the initial phase of revising the whole subfamily. In order to avoid unnecessary overlap and redundancy, and in view of his more comprehensive approach, the present study is now confined to the descriptions of six new species and redescriptions of two misinterpreted taxa that were needed for comparison.

\section{Material and methods}

The material treated in this study is deposited in the following public and private collections:

BMNH The Natural History Museum, London (M. Barclay)

IRSNB Institut Royal des Sciences Naturelles de Belgique, Bruxelles (Y. Gérard)

MNB Museum für Naturkunde, Berlin, coll. Schülke (M. Schülke)

NME Naturkundemuseum Erfurt (M. Hartmann)

SMNH Swedish Museum of Natural History, Stockholm (J. Bergsten)

cAss author's private collection

cPüt private collection Andreas Pütz, Eisenhüttenstadt

cSme private collection Aleš Smetana, Ottawa

cWei private collection Andreas Weigel, Wernburg

The morphological studies were conducted using a Stemi SV 11 microscope (Zeiss), a Discovery V12 microscope
(Zeiss), and a Jenalab compound microscope (Carl Zeiss Jena). The images were created using a digital camera (Nikon Coolpix 995), Axiocam ERc 5s, and Picolay software, as well as a photographing device constructed by Arved Lompe (Nienburg) and CombineZ software.

Total length was measured from the apices of the mandibles (or the labrum when mandibles were not visible) to the abdominal apex, the length of the forebody from the apices of the mandibles (or the labrum) to the posterior margin of the elytra, pronotal length was measured along the middle, elytral length at the suture from the apex of the scutellum to the posterior margin of the elytra, and the length of the aedeagus from the apices of the parameres to the base of the aedeagal capsule. The "parameral" side (i.e., the side where the sperm duct enters) is referred to as the ventral, the opposite side as the dorsal aspect. The measurements are given in $\mathrm{mm}$.

\section{Descriptions}

\section{Apatetica viridipennis FAuvEL, 1895 \\ (Figs 1-4)}

Apatetica viridipennis FAUvel, 1895: $192 \mathrm{f}$.

Type material examined: Holotype $\sigma^{\star}$ : "Darjeeling, Sikkim / viridipennis Fvl. / R.I.Sc.N.B. 17.479, Apatetica, Coll. et det. A. Fauvel / Type / Holotypus o Apatetica viridipennis Fauvel, rev. V. Assing 2018” (IRSNB).

Comment: The original description is based on "un seul on" from "Sikkim, Darjeeling" (FAuvel 1895).

Redescription: Large species; body length $9.3 \mathrm{~mm}$; length of forebody $7.3 \mathrm{~mm}$. Other measurements: head width $1.7 \mathrm{~mm}$; width of pronotum: $3.6 \mathrm{~mm}$; length of pronotum $2.3 \mathrm{~mm}$; length of elytra $3.6 \mathrm{~mm}$; length of metatibia $2.7 \mathrm{~mm}$. Habitus as in Fig. 1. Coloration: body black, with the lateral margins of the pronotum broadly dark reddish-brown; elytra with moderate metallic greenish hue; legs partly blackish-brown to black with reddish tarsi; antennae red with antennomere I weakly infuscate. Head (Fig. 2) strongly transverse; vertex with extensive flat elevation, this elevation weakly pronounced, glossy, with micropunctation, posteriorly and laterally delimited by areas with very coarse and dense macropunctation; frons glossy and with micropunctation. Antenna very long and slender; antennomeres IV and V four times as long as broad; antennomere $\mathrm{X}$ approximately twice as long as broad.

Pronotum (Fig. 2) approximately 1.5 times as broad as long and 2.1 times as broad as head, broadest at posterior third; median portion of disc strongly elevated ("domeshaped"); lateral margins broadly explanate, with shallow microsculpture predominantly composed of longitudinal 
striae, each with approximately ten coarse and few finer punctures; punctation of disc very coarse and very dense; along midline with impunctate median band interrupted by a cluster of moderately dense punctures only in the middle.

Elytra approximately 1.55 times as long as pronotum; each elytron with eight finely punctate striae; intervals flat and with dense micropunctation. Scutellum transverse. Legs very long and slender.

Abdomen with microsculpture composed of a mix of dense microgranules and of transverse meshes on tergite $\mathrm{V}$ and of transverse meshes on tergites VI-VIII; punctation of tergite $\mathrm{V}$ fine and rather dense, that of tergite VI fine and sparse, that of tergite VII rather sparse, predominantly fine, and with some interspersed larger punctures, and that of tergite VIII rather dense and very coarse.

$0^{\star}$ : protarsomeres I-IV strongly dilated and flat; tergite VIII wedge-shaped, apically pointed; aedeagus (Figs 3-4) including parameres $2.2 \mathrm{~mm}$ long; ventral process long, slender, tapering apicad, and acute apically in ventral view; parameres slender, apically flattened and bent ventrad, slightly projecting beyond apex of ventral process.

o: : unknown.

Comparative notes: Among the congeners with metallic elytra from continental Asia, A. viridipennis is characterized particularly by the dome-shaped pronotum with very dense and coarse punctation, the coloration, very slender legs and antennae, and by the shape of the aedeagus.

Distribution: The type locality is situated in West Bengal, North India. Records from other regions (Assam, Manipur) require confirmation. Previous records from Myanmar refer to $A$. confusa.

\section{Apatetica glaucipennis spec. nov. urn:Isid:zoobank.org:act:42C008AA-4925-4FC9-AA0B-3F043FC50F97 (Figs 5-10)}

Type material: Holotype $\sigma^{\star}:$ "NEP: Mahakali/Darchula, Godhani, Godhani Khola, N2949'53", E8040'45", 1920 m, 17.VI.2017, leg. A. Weigel, KL \#17-07 / Holotypus o Apatetica glaucipennis sp. n. det. V. Assing 2017" (NME). Paratypes: $1 \sigma^{*}, 3$ 우: same data as holotype (cWei, cAss); $10^{7}$ : same data as holotype, but "16.VI.2017, leg. A. Kopetz, \#17-07” (NME).

Etymology: The specific epithet is an adjective composed of the Latin adjective glaucus (blue) and the suffix - pennis (of the wings). It alludes to the pronounced metallic blue hue of the elytra.

Description: Large species; body length $8.8-10.8 \mathrm{~mm}$; length of forebody $7.7-8.8 \mathrm{~mm}$. Other measurements: head width $1.90-2.05 \mathrm{~mm}$; length of antenna
4.7-5.0 mm; width of pronotum: $4.0-4.2 \mathrm{~mm}$; length of pronotum $2.4-2.6 \mathrm{~mm}$; length of elytra $3.9-4.5 \mathrm{~mm}$; length of metatibia $3.0-3.4 \mathrm{~mm}$. Habitus as in Fig. 5 . Coloration: body black; elytra with pronounced metallic blue or blue-green hue; antennae and legs black except for the reddish-brown tarsomeres $\mathrm{V}$.

Head (Fig. 6) strongly transverse; vertex with extensive flat elevation, this elevation glossy, with micropunctation, and in postero-median portion with a cluster of more or less numerous macropunctures; frons glossy and with micropunctation, laterally with macropunctures; lateral portion behind eye and area near dorsal margin of eye with very dense and coarse punctation. Antenna very long and slender; antennomeres IV and V more than three times as long as broad; antennomere $\mathrm{X}$ approximately 1.5 times as long as broad.

Pronotum (Fig. 6) approximately 1.7 times as broad as long and 2.0-2.1 times as broad as head, broadest at posterior third; lateral margins broadly explanate, with shallow microsculpture predominantly composed of longitudinal striae, each with approximately five marginal punctures; punctation of disc coarse, dense laterally and sparser in the middle; middle and medio-lateral portions of disc with irregular impunctate patches.

Elytra approximately 1.6 times as long as pronotum; each elytron with eight finely punctate striae; intervals flat and with dense micropunctation. Scutellum strongly transverse. Legs very long and slender.

Abdomen with microsculpture composed of dense microgranules on tergite $\mathrm{V}$ and of transverse meshes on tergites VI-VIII; tergite VIII with pronounced sexual dimorphism.

$\mathrm{o}^{\star}$ : protarsomeres I-IV strongly dilated and flat; tergite VIII (Fig. 7) wedge-shaped, apically obtusely pointed, across the middle with a broad transverse band of numerous coarse punctures; aedeagus (Figs 8-9) $3.3 \mathrm{~mm}$ long; ventral process long, slender, tapering apicad, and very acute apically in ventral view, apical two-fifths distinctly bent dorsad in lateral view; parameres slender, apically flattened and bent ventrad, approximally extending to apex of ventral process.

+: protarsomeres I-IV dilated, but somewhat less so than in male; tergite VIII (Fig. 10) with punctation as in male, but apically strongly and broadly concave.

Comparative notes: Apatetica glaucipennis is distinguished from other congeners with metallic elytra from continental Asia as follows:

from A. lebioides Westwood, 1848 (India: Sikkim; type material examined) by larger size (A. lebioides: body length $6-7 \mathrm{~mm}$ ), the coloration (A. lebioides: lateral margins of the pronotum, tibiae, tarsi, and antennae yellowish-red to reddish; elytra with greenish hue), an anteriorly more strongly tapering abdomen with much sparser and coarser punctation (A. lebioides: pronotum only slightly more narrowed anteriorly than posteriorly). and a coarsely punctured tergite VIII (A. lebioides: tergite VIII practically impunctate); 


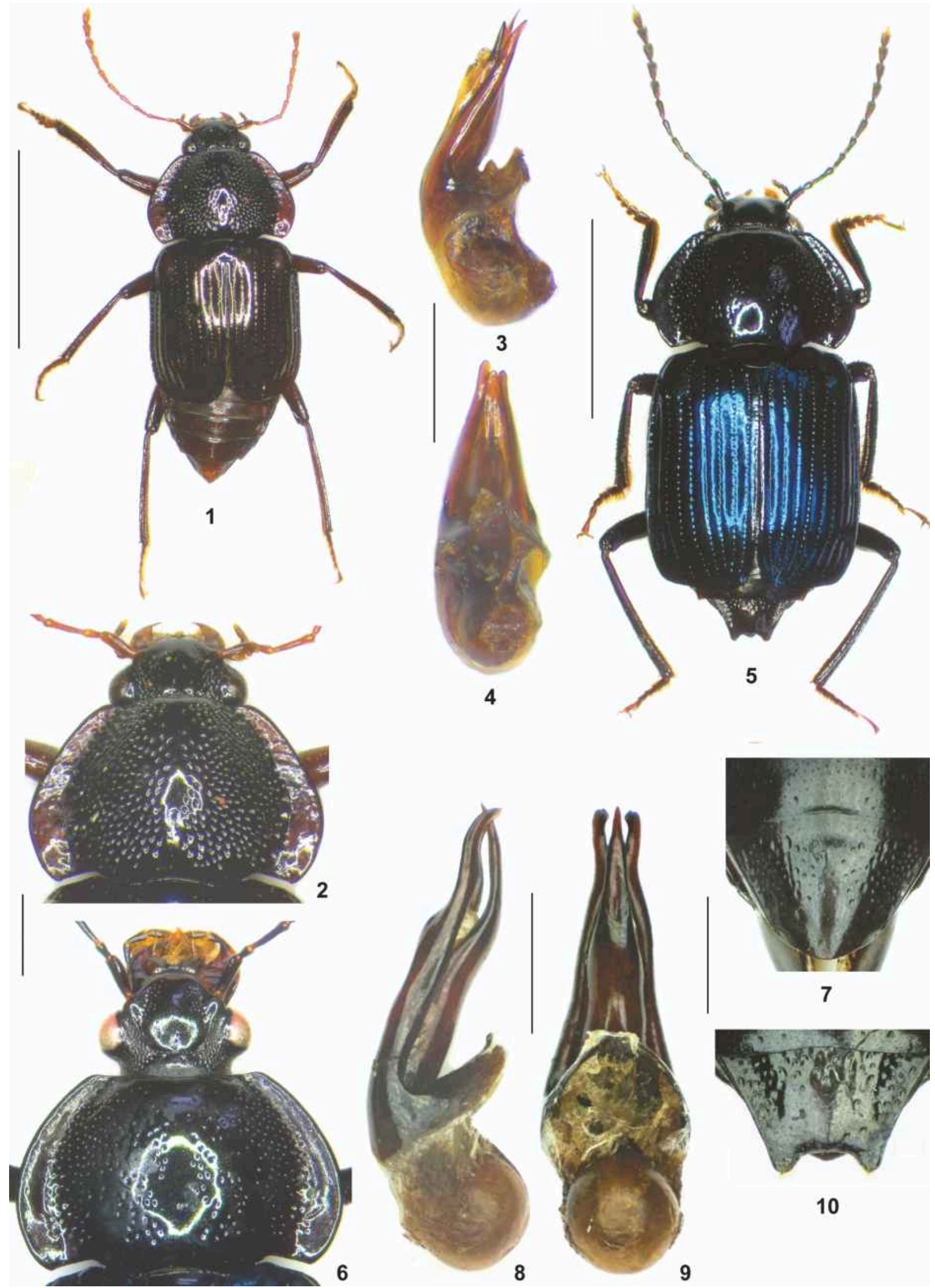

Figs 1-10: Apatetica viridipennis (1-4) and A. glaucipennis (5-10): habitus $(1,5)$; head and pronotum $(2,6)$; aedeagus in lateral and in ventral view (3-4, 8-9); male tergite VIII (7); female tergite VIII (10). Scale bars: 1, 5: 5.0 mm; 2-4, 6-10: $1.0 \mathrm{~mm}$. 
from A. viridipennis (Northeast India: West Bengal, Assam?, Manipur?) by a more robust habitus, the coloration (A. viridipennis: antennae and tarsi reddish; lateral margins of pronotum dark reddish-brown; elytra with greenish hue), and by a less convex pronotum (cross-section) with much sparser and finer punctation (A. viridipennis: median portion of pronotum dome-shaped);

from A.caeruleipennis CAMERoN, 1930 (NE-India: Manipur; type material examined) by a less strongly convex pronotum (cross-section) with much sparser, finer, and irregular punctation (A. caeruleipennis: pronotum with extremely dense, coarse, and uniform punctation; interstices reduced to narrow ridges; median portion strongly elevated, similar to the condition in A. viridipennis)

from A. birmana CAMERon, 1930 (Myanmar; type material examined) by the coloration (A. birmana: apical antennomeres and tarsi reddish; elytra with indistinct metallic hue) and by a less convex pronotum (cross-section) with sparser and more irregular punctation and with practically impunctate lateral margins (A. birmana: lateral margins with coarse and rather dense punctation).

from A. siamensis Lewis, 1893 (Thailand; type material examined) by slightly larger size (A. siamensis: $8 \mathrm{~mm}$ ), the coloration (A. siamensis: antennae and tarsi reddish brown, lateral margins of pronotum dark reddish-brown; elytra with weak greenish hue), the punctation of the pronotum (A. siamensis: whole pronotum including lateral margins with dense and more or less regularly spaced punctation), and by the shape of the female tergite VIII (A. siamensis: tergite VIII with bisinuate apex and with longitudinal median elevation).

Distribution and natural history: The type locality is situated in the extreme west of Nepal. The specimens were beaten from moist rotting plant material at a river bank (WEIGEL pers. comm.).

\section{Apatetica confusa spec. nov. urn:Isid:zoobank.org:act:03A55D46-5010-43D8-BFEF-9D02E3BE2D1A (Figs 11-14)}

Type material: Holotype $0^{\top}:$ "N. E. BURMA, Kambaiti, 7000 ft., 12/5 1934, R. Malaise / 6382, E91 / Apatetica ?viridipennis Fauv., A. Jansson det. / NHRS-JLKB 000027544 / Holotypus o Apatetica confusa sp. n. det. V. Assing 2018” (SMNH). Paratypes: 1 ․ "N. E. BURMA, Kambaiti, 2000 m, 17/5.1934, Malaise / 6381, E91 / NHRS-JLKB 000027543” (SMNH); 1 ㅇ:"N. E. BURMA, Kambaiti, 2000 m, 17/5.1934, Malaise / Brit. Mus. 1948-480 / Apatetica ?viridipennis Fauv." (BMNH); 1 우 "N. E. BURMA, Kambaiti, 2000 m, 1/6.1934, Malaise / 6380, E91 / NHRS-JLKB 000027542” (cAss); 3 우 우: “Doherty / Birmah, Ruby M"es" (BMNH, cAss).
Etymology: The specific epithet is the past participle of the Latin verb confundere and alludes to the fact that the above specimens were previously confounded with A. viridipennis.

Description: Rather large species; body length $8.8-9.3 \mathrm{~mm}$; length of forebody $8.2-9.0 \mathrm{~mm}$. Other measurements: head width $1.8-1.9 \mathrm{~mm}$; length of antenna 4.7-5.0 $\mathrm{mm}$; width of pronotum: $3.6-3.9 \mathrm{~mm}$; length of pronotum $2.2-2.4 \mathrm{~mm}$; length of elytra $3.9-4.5 \mathrm{~mm}$; length of metatibia $2.9-3.0 \mathrm{~mm}$. Habitus as in Fig. 11. Coloration: body black; elytra with more or less pronounced metallic hue of usually greenish-coppery, rarely blue or violet colour; legs: femora black; tibiae usually basally black and apically slightly paler, rarely completely black; tarsi usually reddish, rarely darker; antennae reddish with antennomere I infuscate.

Head (Fig. 12) strongly transverse; vertex glossy, with micropunctation, and in postero-median portion usually with few larger punctures; frons glossy and with micropunctation; lateral portion behind eye and area near dorsal margin of eye with dense and coarse punctation. Antenna very long and slender; antennomeres IV and V more than three times as long as broad; antennomere $\mathrm{X}$ approximately twice as long as broad.

Pronotum (Fig. 12) approximately 1.6 times as broad as long and twice as broad as head, broadest at posterior third; disc moderately convex in cross-section; lateral margins broadly explanate, with shallow microsculpture predominantly composed of longitudinal striae, each with approximately 15-20 punctures; punctation of disc coarse, dense antero-laterally, sparser postero-laterally; midline more or less broadly impunctate.

Very shallow traces of microsculpture visible only at high magnification.

Elytra approximately 1.7 times as long as pronotum; each elytron with eight finely punctate striae; intervals flat and with sparse micropunctation. Scutellum transverse. Legs very long and slender.

Abdomen with microsculpture composed of dense microgranules on tergite $\mathrm{V}$, of transverse meshes on tergites VI, and of a mix of transverse and isodiametric meshes on tergites VII-VIII; tergites VI and VII with fine and sparse, tergite VIII with denser and more distinct punctation; tergite VIII with pronounced sexual dimorphism.

$\mathrm{o}^{*}$ : protarsomeres I-IV strongly dilated and flat; tergite VIII wedge-shaped, apically pointed; aedeagus (Figs 13-14) $2 \mathrm{~mm}$ long; ventral process long, slender, tapering apicad, apically nearly truncate in ventral view, distinctly bent dorsad in lateral view; parameres rather stout and straight, apically flattened and truncate, approximally extending to apex of ventral process.

i : protarsomeres I-IV dilated, but somewhat less so than in male; tergite VIII apically bisinuate.

Comparative notes: In size, habitus, punctation, and other external characters, A. confusa is most similar to A. glaucipennis, from which it is distinguished by the 

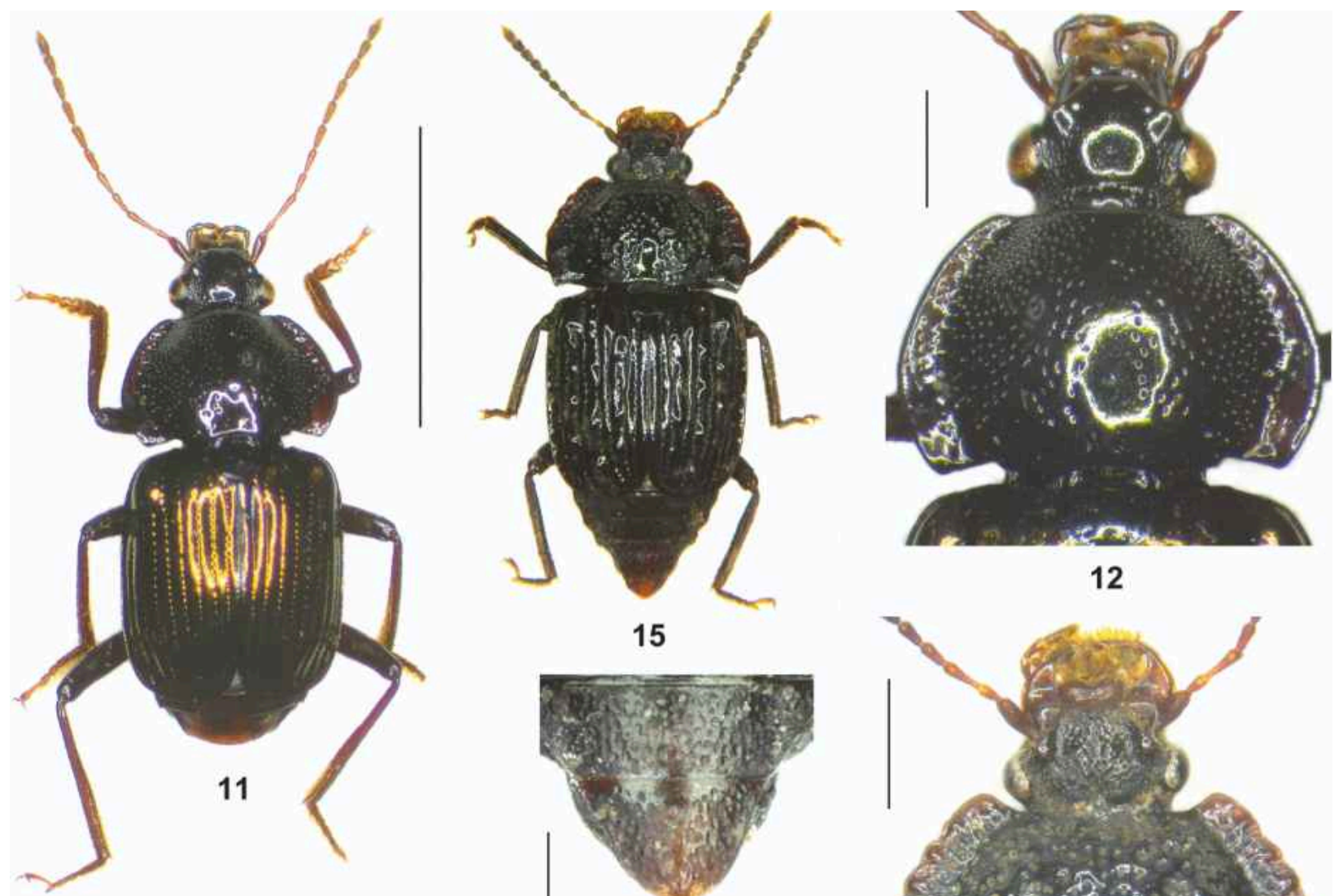

12

15
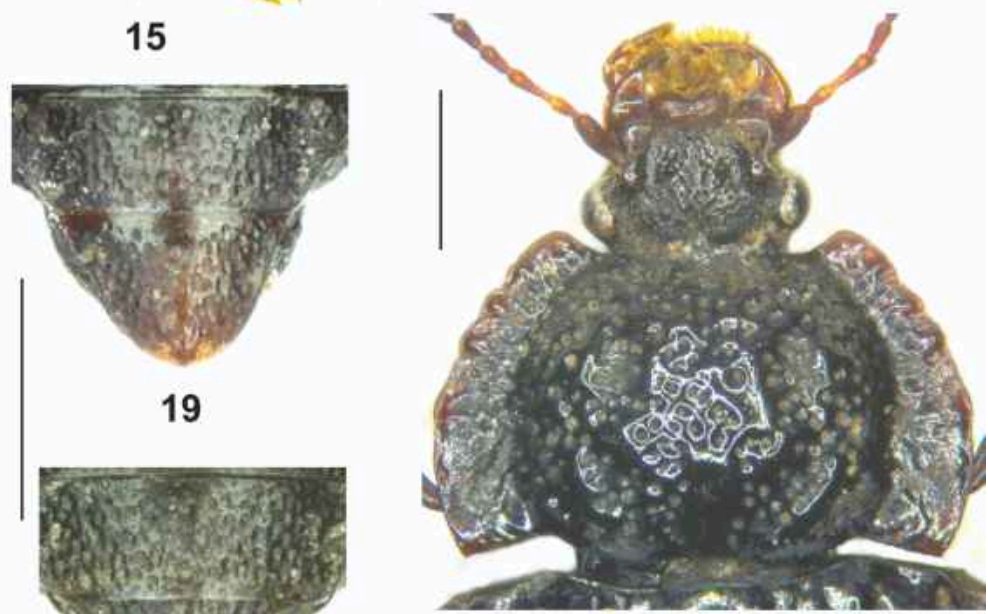

17

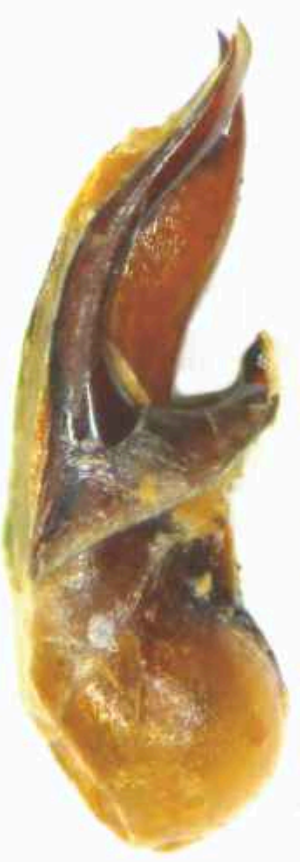

13

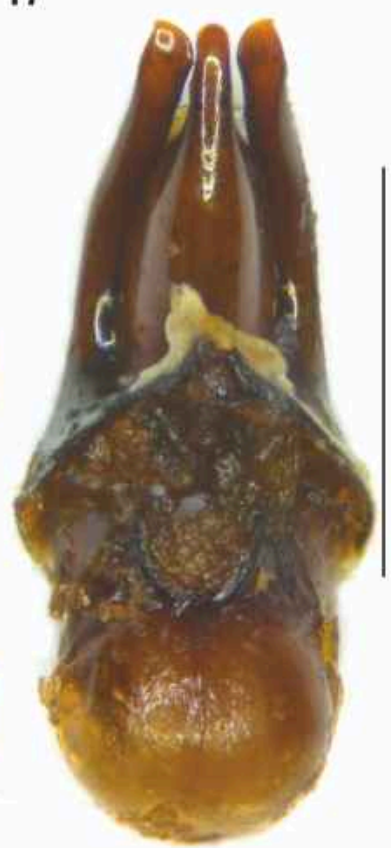

14
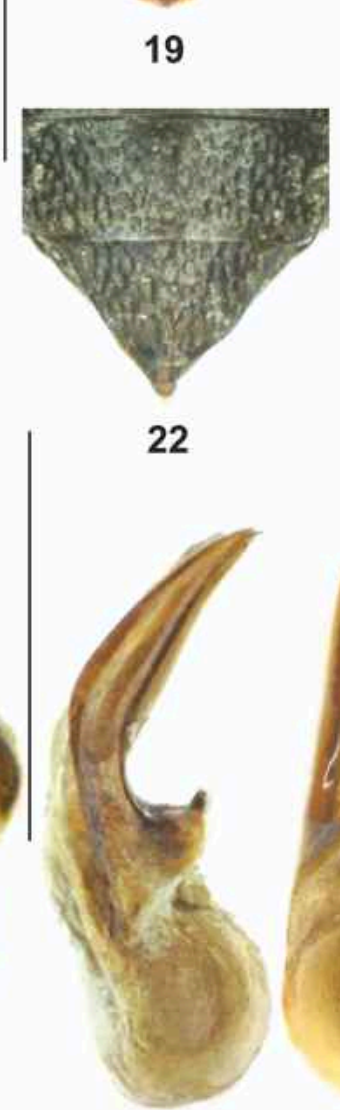

20

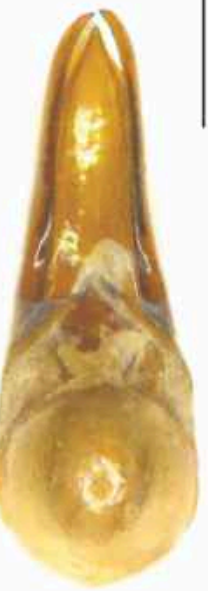

21

Figs 11-22: Apatetica confusa (11-14) and A. aspera (15-22): habitus (11, 15); head and pronotum $(12,16)$; aedeagus in lateral and in ventral view (13-14, 20-21); antenna (17); anterior portion of left elytron (18); male tergites VII-VIII (19); female tergites VIIVIII (22). Scale bars: 11, 15: 5.0 mm; 12-14, 16-22: 1.0 mm. 
coloration of the antennae, the tarsi, and the elytra, by more slender preapical antennomeres, the punctation of the head and the disc of the pronotum, much more numerous punctures on the explanate margins of the pronotum, and by a much smaller aedeagus with a ventral process and parameres of different shapes. It is readily distinguished from $A$. viridipennis by the different pronotal punctation and especially the medially much less elevated pronotal disc alone.

Distribution and natural history: At present, the species is reliably known only from two localities in Myanmar. The specimens from the type locality were collected between 2000 and approximately $2100 \mathrm{~m}$ in May and June.

\section{Apatetica aspera spec. nov. urn:Isid:zoobank.org:act:221E2344-6290-429C-930E-32F970F7DD72 (Figs 15-22)}

Type material: Holotype $0^{\star}$ : “CHINA [32] - S-Shaanxi [recte: N-Sichuan], Micang Shan, $42 \mathrm{~km} \mathrm{~S} \mathrm{Hanzhong,}$ $32^{\circ} 40^{\prime} 43^{\prime \prime N}, 106^{\circ} 48^{\prime} 33^{\prime \prime E}, 1090$ m, 17.VIII.2012, V. Assing / Holotypus o Apatetica aspera sp. n. det. V. Assing 2017" (cAss). Paratypes: 2 ㅇ $\circ$ : same data as holotype (cAss); $10^{\star}$ [damaged: abdominal segments VIII-X missing]: "China, Sichuan, Qingcheng Shan, $65 \mathrm{~km} \mathrm{NW}$ Chengdu, 103.33E, 30.53N, 18.V./3.-4.VI.1997, 8 km W Taiping, 800-1000 m, leg. A. Pütz" (cPüt); 1 \%: "China (Sichuan) 1995, Qingcheng-shan (Umg. Heavenly Old Village) 1000-1300 m, 18./20.VI. Heinz leg." (cSme); 1 ex. [damaged; abdominal apex missing]: "CHINA (C-Sichuan) (17) Quincheng [sic] Shan, NW Chengdu, 650-700 m, 30.54N, 103.33E, 3./4.VI.1997 Wrase" (MNB); 1 : : "CHINA border Shaanxi-Sichuan Daba

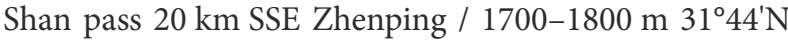
$109^{\circ} 35^{\prime}$ E, 9.VII.2001, A. Smetana [C96b]" (cSme).

Etymology: The specific epithet (Latin, adjective: rough) alludes to the pronounced sculpture of the dorsal surface of the forebody.

Description: Body length 7.3-8.1 mm; length of forebody $6.3-7.1 \mathrm{~mm}$. Other measurements: head width 1.4-1.6 mm; length of antenna $2.7-3.0 \mathrm{~mm}$; width of pronotum: $3.3-3.5 \mathrm{~mm}$; length of pronotum $1.9-2.0 \mathrm{~mm}$; length of elytra $2.8-3.2 \mathrm{~mm}$; length of metatibia $1.8-1.9 \mathrm{~mm}$. Habitus as in Fig. 15. Coloration: body black with the lateral explanate margins of the pronotum more or less distinctly paler; legs black except for the reddish to reddish-brown tarsomeres V; antennae black with antennomeres II-III and the base of IV reddish-brown.

Head (Fig. 16) strongly transverse; vertex with a pair of flat and coarsely punctured elevations, between these elevations with irregular longitudinal rugae, between elevations and dorsal margins of eyes coarsely rugose; frons with coarse and dense punctation; interstices with shallow striate microsculpture. Antenna (Fig. 17) moderately long; antennomeres IV and V approximately twice as long as broad; antennomere $\mathrm{X}$ weakly oblong.

Pronotum (Fig. 16) approximately 1.7 times as broad as long and approximately 1.35 times as broad as head, broadest at posterior third; lateral margins very broadly explanate, irregularly sculptured, irregularly crenulate, and with moderately coarse punctures in anterior half; disc with extremely coarse punctation and irregular elevations; interstices glossy.

Elytra (Fig. 18) approximately 1.5 times as long as pronotum; each elytron with eight indistinctly and sparsely punctate striae; intervals more or less convex (crosssection), without distinct microsculpture, and glossy; intervals 3, 5, 7, and 9 with two to six pronounced, but somewhat irregular elevations, the number of elevations increasing from interval 3 to 9; near humeral angles with very large elevation. Scutellum weakly transverse. Hind wings present. Legs rather short and stout; protarsomeres I-IV without appreciable sexual dimorphism, moderately dilated in both sexes.

Abdomen (Figs 19, 22) with microsculpture predominantly composed of more or less distinctly isodiametric meshes; punctation of tergites VII and VIII very coarse and dense, much more so than that of $\mathrm{V}$ and VI; tergite VIII (Figs 19, 22) without appreciable sexual dimorphism.

$\mathrm{o}^{\star}$ : aedeagus (Figs 20-21) $1.55 \mathrm{~mm}$ long; ventral process tapering apicad and acute apically in ventral view; parameres slender, apically very acute, not flattened, extending slightly beyond apex of ventral process.

Intraspecific variation: In the two females from the Qingcheng Shan and Daba Shan the middle of abdominal tergite VIII is sparsely punctate to almost impunctate, whereas in the material from the type locality it is coarsely and densely punctate everywhere. The condition in the two remaining specimens cannot be assessed, since their tergites VIII are missing. Since no additional evidence was found suggesting that the respective populations should represent distinct species and since the aedeagus of the male from Qingcheng Shan is identical to that of the holotype, the observed difference is attributed to intraspecific variation.

Comparative notes: This species is similar and evidently closely allied to Apatetica callosa Jansson, 1947 (type locality: Kambaiti pass in Northeast Myanmar; holotype examined), but distinguished by a more coarsely and densely punctured head (especially in anterior portion), blackish antennomeres X-XI (reddish in A. callosa), the shape and sculpture of the pronotum (A. callosa: median portion more elevated, more strongly convex in cross-section; distribution of callosities different; lateral margins anteriorly dentate), the distribution and shapes of the elevations on the elytra (A. callosa: elevations more oblong, more pronounced, and more defined), and by 
the shape of the aedeagus (A. callosa: median lobe more strongly curved in lateral view; ventral process apically narrower and more acute).

Distribution and natural history: Apatetica aspera is currently known from five localities in the Micang Shan, the Qingcheng Shan, and the Daba Shan in North and Central Sichuan, China. The altitudes range from approximately 700 to approximately $1750 \mathrm{~m}$. The specimens from the type locality, one of which is teneral, were sifted from leaf litter and the roots of grass and herbs along a path at the margin of a secondary mixed forest.

\section{Apatetica laevicollis FAUVEL, 1904}

(Figs 23-28)

Apatetica laevicollis FAUvel, 1904: $86 \mathrm{f}$.

Type material examined: Lectotype $\sigma^{\top}$ [teneral], present designation: "Central-Tonkin, Chiem-Hoa, Aug. Sept., H. Fruhstorfer / laevicollis Fvl. / R.I.Sc.N.B. 17.479, Apatetica, Coll. et det. A. Fauvel / Type / Lectotypus ơ Apatetica laevicollis Fauvel, desig. V. Assing 2018” (IRSNB).

Comment: The original description is based on an unspecified number of syntypes from "Tonkin central : Chiem-Hoa" (Fauvel 1904). The sole syntype in the Fauvel collection (IRSNB), a teneral male, is designated as the lectotype.

Additional material examined: Vietnam: $1 \sigma^{\star}$, Cao Bang Province, Tinh Tuc env., Son Dong Nui Pia Nature Reserve, $22^{\circ} 37^{\prime} \mathrm{N}, 105^{\circ} 53^{\prime} \mathrm{E}, 900-1100 \mathrm{~m}$, bamboo forest, 13.V.2014, leg. Weigel (cWei).

Redescription: Body length $7.0 \mathrm{~mm}$; length of forebody $5.5-6.0 \mathrm{~mm}$. Other measurements: head width $1.4-1.5 \mathrm{~mm}$; length of antenna $2.9-3.1 \mathrm{~mm}$; width of pronotum: $3.1-3.3 \mathrm{~mm}$; length of pronotum $1.7-1.8 \mathrm{~mm}$; length of elytra $2.8-3.0 \mathrm{~mm}$; length of metatibia $1.6 \mathrm{~mm}$. Habitus as in Fig. 23. Coloration: body including the appendages black, except for the reddish to reddish-brown base of antennomere III and meso- and metatarsomeres III-V, and the pale-reddish protarsi.

Head (Fig. 24) strongly transverse; vertex without microsculpture, with a pair of glossy patches with micropunctation separated by an oblong and weakly impressed area with coarse punctation; between vertex and dorsal margin of eyes with coarse longitudinal sculpture; frons with rather fine to coarse punctation and without microsculpture. Antenna moderately long; antennomeres IV and V approximately twice as long as broad, VI and VIII weakly oblong, and IX and X approximately as long as broad.

Pronotum (Fig. 24) approximately 1.8 times as broad as long and approximately 2.2 times as broad as head, broadest near posterior angles; disc moderately convex in cross-section, near posterior angles flattened; posterior angles sharply marked and directed posteriad; lateral margins narrowly separated and of subequal width along their whole length; macropunctation very sparse (additional specimen) to scattered (lectotype), moderately coarse, and very irregularly distributed on disc, somewhat denser and more regularly distributed only along lateral margins; whole disc with moderately dense micropunctation; interstices without microsculpture.

Elytra approximately 1.65 times as long as pronotum; each elytron with eight finely and densely punctate striae; intervals flat, with micropunctation, but without distinct microsculpture and glossy. Scutellum weakly transverse. Legs rather short and stout; protarsomeres I-IV probably without sexual dimorphism.

Abdomen (Fig. 25) with shallow transverse microsculpture; punctation of tergites VI and VII rather coarse and dense, that of tergite VIII somewhat less dense; tergite VIII strongly convex in cross-section, distinctly tapering posteriad.

$\sigma^{*}$ : protarsomeres I-IV weakly dilated; aedeagus (Figs 26-28) approximately $1.3 \mathrm{~mm}$ long; ventral process tapering apicad and very acute (needle-shaped) apically in ventral view; parameres slender, apically acute and flattened, extending slightly beyond apex of ventral process.

Comparative notes: Apatetica laevicollis is characterized by practically completely black colour, moderate body size, broad and relatively weakly convex (cross-section) pronotum and elytra, the near absence of macropunctation on the disc of the pronotum, short legs, and by the shape of the aedeagus. Among the described congeners recorded from continental Asia, A. laevicollis is similar only to the following species. For distinguishing characters see the comparative notes in the section on A. glabra.

Distribution and natural history: The species is currently known only from two localites in Central and Northeast Vietnam. The record from the Chinese province Sichuan (Schülke \& SMetana 2015) is based on a misidentification and refers to A. gibba spec. nov. (see below). The additional male recorded above was collected in a bamboo forest at an altitude of 900-1100 m. The lectotype is distinctly teneral.

\section{Apatetica glabra spec. nov. urn:Isid:zoobank.org:act:01C0EC41-4144-4C16-812E-1A8A7507673C (Figs 29-33)}

Type material: Holotype $\sigma^{\star}$ : "CHINA [20b] - Yunnan, mt. W Gejiu, mixed forest, $23^{\circ} 24^{\prime} 13^{\prime \prime} \mathrm{N}, 103^{\circ} 07^{\prime} 28^{\prime \prime} \mathrm{E}$, 1990 m, 25.VIII.2014, V. Assing / Holotypus ơ Apatetica glabra sp. n. det. V. Assing 2017” (cAss). Paratypes: $10^{\text {* }}$ : "CHINA [13] - Yunnan, mt. SE Gejiu, graveyard with 


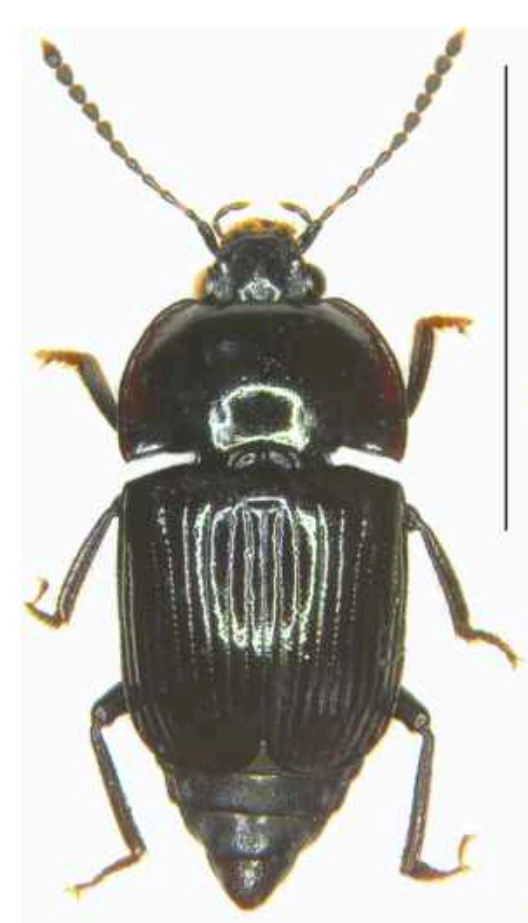

23

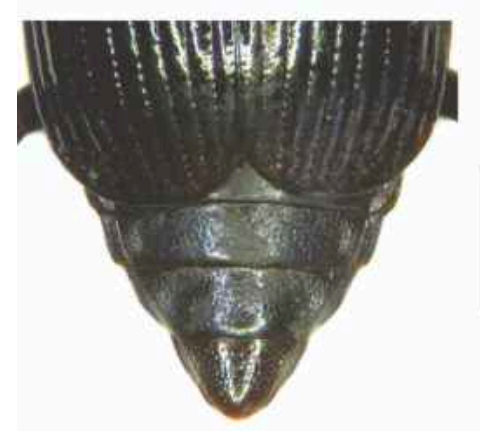

25

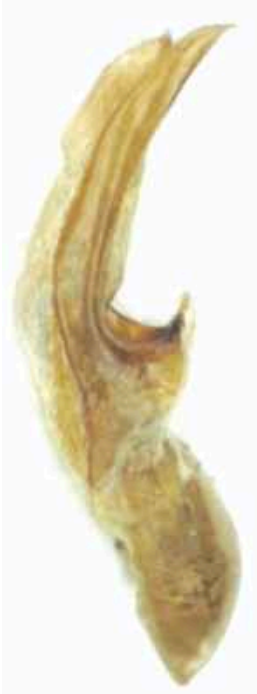

26

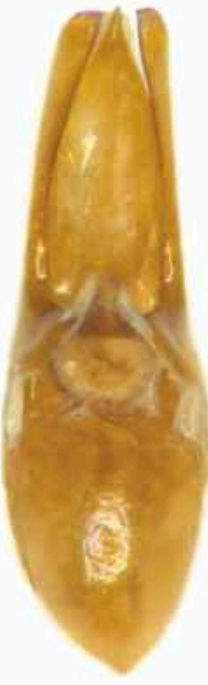

27

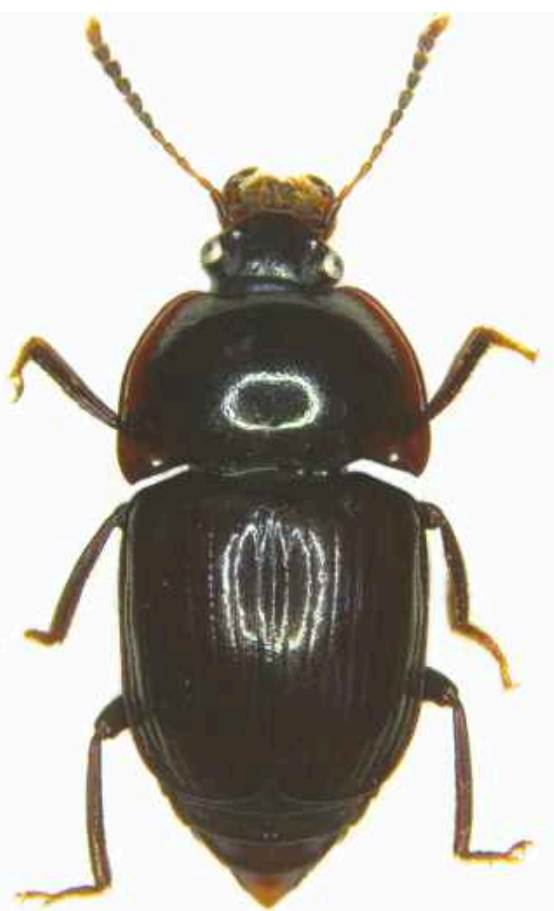

29

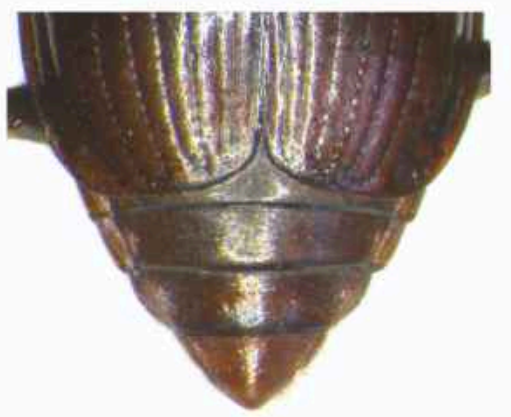

31

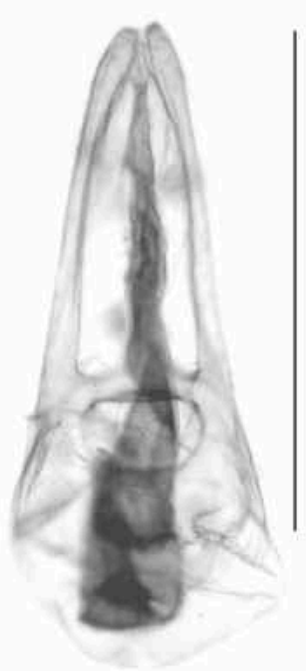

28

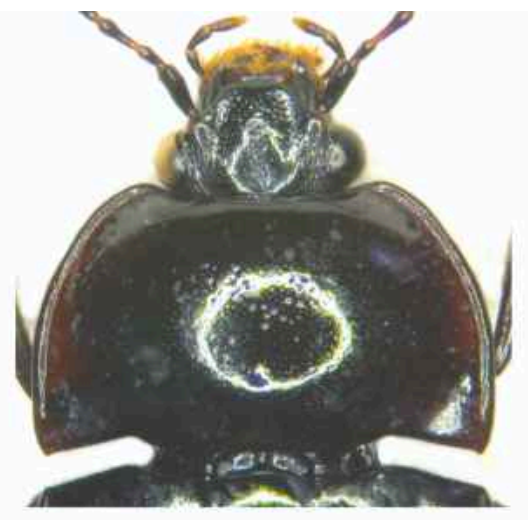

24

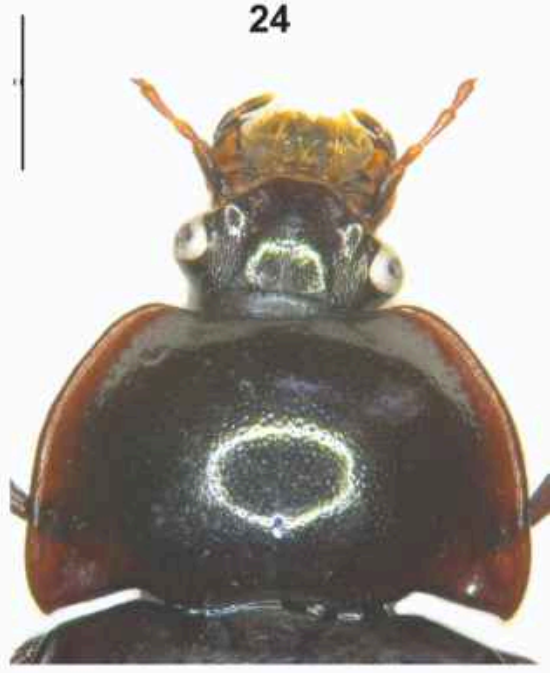

30

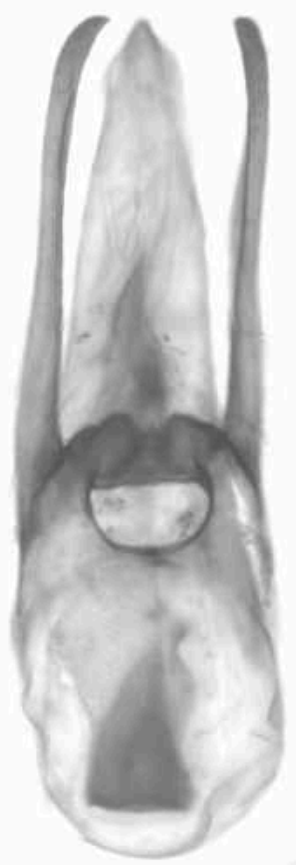

33

Figs 23-33: Apatetica laevicollis (23-28) and A. glabra (29-33): habitus (23, 29); head and pronotum (24, 30); posterior portion of elytra and abdomen $(\mathbf{2 5}, \mathbf{3 1})$; aedeagus in lateral and in ventral view (26-28, 32-33; 28: lectotype). Scale bars: 23, 29: 5.0 mm; 24-28, 30-33: $1.0 \mathrm{~mm}$. 
pine, $23^{\circ} 18^{\prime} 27^{\prime \prime} \mathrm{N}, 103^{\circ} 11^{\prime} 41^{\prime \prime E}, 2400 \mathrm{~m}, 20$. VIII.2014, V. Assing" (cAss); $10^{\star}$ : "CHINA: Yunnan, mountain W Gejiu, $23^{\circ} 24^{\prime} 13^{\prime \prime N}, 103^{\circ} 07^{\prime} 28^{\prime \prime E}, 1990 \mathrm{~m}$, misted [sic] forest, litter and various debris sifted, 23.VIII.2014, leg. M. Schülke [CH14-20]" (MNB).

Etymology: The specific epithet (Latin, adjective) alludes to the fine punctation of the forebody.

Description: Body length 7.4-8.2 $\mathrm{mm}$; length of forebody $6.3-6.8 \mathrm{~mm}$. Other measurements: head width $1.5-1.6 \mathrm{~mm}$; length of antenna $2.8-3.0 \mathrm{~mm}$; width of pronotum: $3.4 \mathrm{~mm}$; length of pronotum $1.9-2.0 \mathrm{~mm}$; length of elytra $3.1-3.3 \mathrm{~mm}$; length of metatibia 1.7-1.8 mm. Habitus as in Fig. 29. Coloration: body black with the lateral margins of the pronotum and tergite VIII dark reddish-brown; legs black with all or the apical joints of the tarsi reddish to reddish-brown; antennae black with antennomeres II-V reddish and I and XI brown.

Head (Fig. 30) strongly transverse; frons and vertex with fine punctation and without microsculpture, glossy; median portion of vertex with or without impression and with a variable number of coarser punctures; near dorsal margin of eyes with rather shallow rugose striae and with longitudinal microsculpture. Antenna moderately long; antennomeres IV approximately twice as long as broad, V nearly twice as long as broad, VI approximately 1.5 times as long as broad, VII weakly oblong, VIII approximately as long as broad, and IX-X weakly transverse.

Pronotum (Fig. 30) 1.7-1.8 times as broad as long and approximately 2.2 times as broad as head, broadest near posterior angles; disc strongly convex in cross-section, near posterior angles flattened; posterior angles sharply marked and directed posteriad; lateral margins narrowly separated in anterior half; disc with regularly distributed and moderately dense fine punctation; interstices without microsculpture.

Elytra approximately 1.65 times as long as pronotum; each elytron with eight fine striae with very fine, rather weakly defined, and not very dense punctures; intervals flat, with extremely fine micropunctation visible only at high magnification, without microsculpture and glossy. Scutellum weakly transverse. Legs rather short and stout; protarsomeres I-IV probably without sexual dimorphism.

Abdomen (Fig. 31) with microsculpture composed of a mix of isodiametric and transverse meshes of variable length; punctation fine, slightly coarser only in lateral portions of tergite VII and in posterior portion of tergite VIII; tergite VIII apically obtusely pointed, gradually becoming more convex (cross-section) from base to apex.

$\sigma^{*}$ : protarsomeres I-IV weakly dilated; aedeagus (Figs 32-33) $1.7 \mathrm{~mm}$ long; ventral process moderately acute apically in ventral view, bent dorsad in lateral view; internal sac with long membranous tube; parameres flat- tened, apically acute and bent ventrad, extending to apex of ventral process.

Comparative notes: Apatetica glabra is distinguished from the otherwise similar A. laevicollis by larger body size, the coloration of the pronotum and the antennae, fine and regularly distributed punctation of the head and pronotum, finer and less dense punctation of the elytral striae, the microsculpture and punctation of the abdominal tergites, the shape of tergite VIII, and by a much larger aedeagus with a ventral process and parameres of different shapes.

Distribution and natural history: The species is known from two localities in the environs of Gejiu, Southeast Yunnan, China. The holotype and one of the paratypes were sifted from litter and various debris in a mixed forest with rich undergrowth at an altitude of $1990 \mathrm{~m}$. For an illustration of the type locality see figure 8 in Assing (2014). The other paratype was sifted from pine litter and herb roots in a graveyard with old pine trees at an altitude of $2400 \mathrm{~m}$.

\section{Apatetica gibba spec. nov. urn:Isid:zoobank.org:act:51D50FDD-A847-43CC-9760-A14D6BC90FE5 (Figs 34-38)}

Type material: Holotype $0^{*}$ : "CHINA: S-Gansu [CH1206] 2012, W-Qinling Shan, $47 \mathrm{~km} \mathrm{~N}$ Chengxian, $34^{\circ} 10^{\prime} 20^{\prime \prime} \mathrm{N}, 105^{\circ} 42^{\prime} 10^{\prime \prime} \mathrm{E}, 1830 \mathrm{~m}$, creek valley with second. deciduous forest, litter sifted, 29.VII. Schülke / Holotypus o Apatetica gibba sp. n. det. V. Assing 2018” (MNB). Paratype $\%$ : "CHINA [6] - S-Gansu, N Chengxian, W-Qinling Shan, 34 $10^{\prime} 20^{\prime \prime} \mathrm{N}, 105^{\circ} 42^{\prime} 10^{\prime \prime E}, 1830 \mathrm{~m}$, 29.VII.2012, V. Assing" (cAss).

Etymology: The specific epithet (Latin, adjective: domed, convex) alludes to strongly convex pronotum (crosssection), one of the characters distinguishing this species from the similar A. laevicollis.

Description: Body length $6.6-6.8 \mathrm{~mm}$; length of forebody $5.6-5.8 \mathrm{~mm}$. Other measurements: head width 1.3-1.4 mm; length of antenna $2.7-2.9 \mathrm{~mm}$; width of pronotum: $2.7-2.9 \mathrm{~mm}$; length of pronotum $1.6 \mathrm{~mm}$; length of elytra $2.6-2.8 \mathrm{~mm}$; length of metatibia 1.5-1.6 mm. Habitus as in Fig. 34. Coloration: body black with the lateral margins of the pronotum dark reddish-brown, the apices of the elytra brown, the posterior margins of the abdominal segments VI-VII dark-reddish, and tergite VIII reddish-yellow to reddishbrown; legs dark-brown to blackish with tarsomeres I-IV brown and tarsomeres $\mathrm{V}$ dark-yellow; antennae black with the basal three to five antennomeres reddish to dark reddish-brown.

Head (Fig. 35) strongly transverse; frons and vertex with moderately fine and rather dense punctation and with 

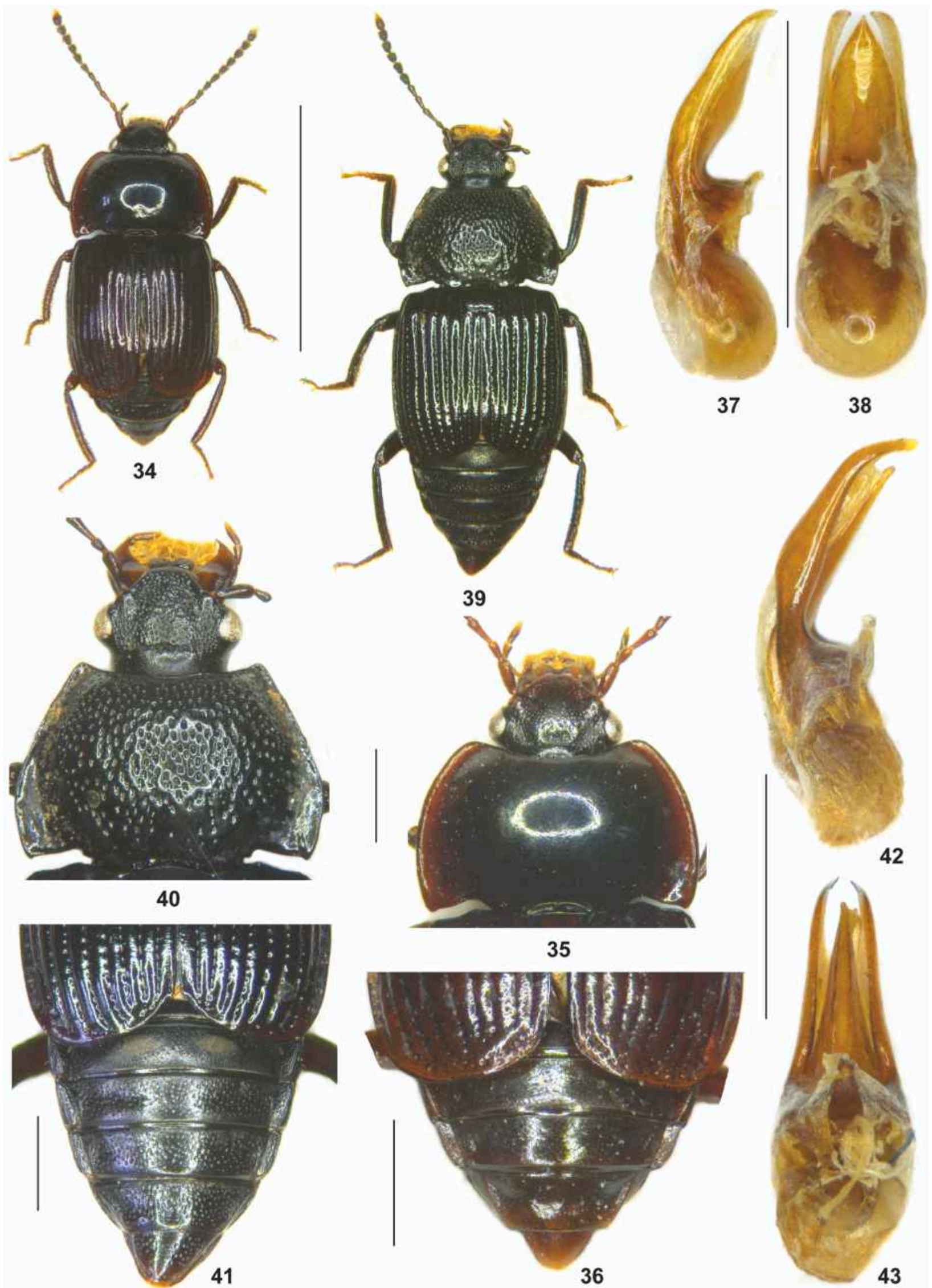

35
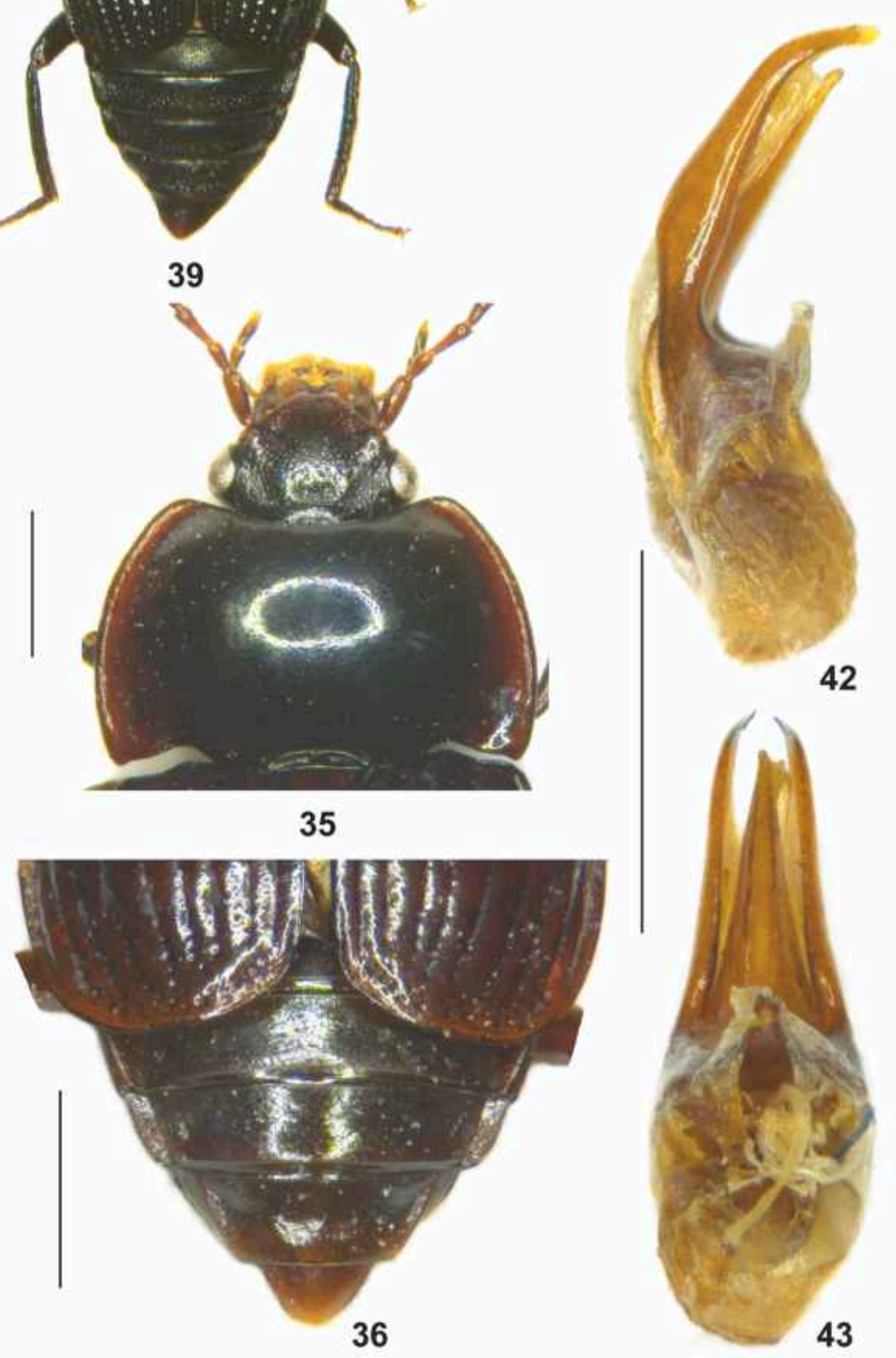

Figs 34-43: Apatetica gibba (34-38) and A. curtipennis (39-43): habitus (34, 39); head and pronotum (35, 40); posterior portion of elytra and abdomen $(36,41)$; aedeagus in lateral and in ventral view $(37-38,42-43)$. Scale bars: 34,39 : $5.0 \mathrm{~mm}$; 35-38, 40-43: $1.0 \mathrm{~mm}$. 
shallow microsculpture; median portion of vertex weakly elevated, nearly flat; near dorsal margin of eyes with very dense and somewhat coarser punctures and with distinct microsculpture. Antenna moderately long; antennomeres IV and V approximately twice as long as broad, VI nearly twice as long as broad, VII approximately 1.5 times as long as broad, VIII and IX weakly oblong, and $\mathrm{X}$ approximately as long as broad.

Pronotum (Fig. 35) approximately 1.7-1.8 times as broad as long and approximately 2.1 times as broad as head, broadest near posterior angles; disc strongly convex in cross-section, near posterior angles flattened; posterior angles sharply marked and directed posteriad; lateral margins narrowly separated in anterior half; disc with regularly distributed dense and extremely fine punctation; interstices with very shallow, partially nearly obsolete microsculpture.

Elytra 1.63-1.75 times as long as pronotum; each elytron with eight fine and mostly impunctate striae (punctures may be weakly indicated in places, particularly in the posterior portion of the elytra); intervals flat, with scattered and extremely fine micropunctation visible only at high magnification, without microsculpture and glossy. Scutellum weakly transverse. Legs rather short and stout; protarsomeres I-IV weakly dilated, without sexual dimorphism.

Abdomen (Fig. 36) with microsculpture composed of a mix of isodiametric and transverse meshes of variable length; punctation fine and rather sparse; tergite VIII sexually dimorphic.

$\sigma^{*}$ : tergite VIII distinctly tapering posteriad, with the posterior margin strongly convex; aedeagus (Figs 37-38) $1.7 \mathrm{~mm}$ long; ventral process acute apically in ventral view, not bent dorsad in lateral view; parameres flattened, apically acute and bent ventrad, extending slightly beyond apex of ventral process.

ㅇ: tergite VIII more distinctly wedge-shaped than in male, with the apex narrowly truncate.

Comparative notes: Based on the similar external and male sexual characters, A. gibba is closely allied to A. laevicollis and A. glabra. It is distinguished from them as follows:

from A. laevicollis by a much more convex pronotum (cross-section), the coloration (A. laevicollis: pronotum, elytra, antennae, and abdomen completely black), a head with distinct microsculpture and finer, more regularly distributed, and less dense punctation, a much more convex pronotum without macropunctation, with finer and denser micropunctation, and with microsculpture, elytra with mostly impunctate striae and with very scattered micropunctation, an abdomen with much finer and much sparser punctation, and by an apically less acute median lobe of the aedeagus;

from A. glabra by smaller body size, a less broad habitus, the presence of microsculpture on the head and the pronotum, the absence of distinct rugae near the dorsal margins of the eyes, much finer punctation of the pronotum, nearly impunctate striae of the elytra, and a distinctly smaller aedeagus with a less slender median lobe.

Distribution and natural history: The type locality is situated in the western portion of the Qinling Shan in South Gansu. The type specimens were sifted from moist litter in a dense secondary deciduous forest with rich undergrowth at an altitude of $1830 \mathrm{~m}$.

\section{Apatetica curtipennis spec. nov. urn:Isid:zoobank.org:act:B7194436-4CE7-4826-BBE6-C23559533C3E (Figs 39-43)}

Type material: Holotype $o^{\top}$ : “CHINA: Yunnan, Baoshan Pref., Gao-ligong [sic] Shan, $78 \mathrm{~km} \mathrm{~N}$ Tengchong, $2000 \mathrm{~m}, 25^{\circ} 44^{\prime} 49^{\prime \prime} \mathrm{N}, 98^{\circ} 33^{\prime} 29^{\prime \prime} \mathrm{E}$, cleft with creek and forest remnant, litter \& dead wood sifted, 1.IX.2009, leg. M. Schülke [CH09-21] / Holotypus ơ Apatetica curtipennis sp. n. det. V. Assing 2018” (MNB).

Etymology: The specific epithet (Latin, adjective: with short wings) alludes to the remarkably short elytra.

Description: Body length $8.9 \mathrm{~mm}$; length of forebody $6.7 \mathrm{~mm}$. Other measurements: head width $1.5 \mathrm{~mm}$; length of antenna $3.2 \mathrm{~mm}$; width of pronotum: $3.2 \mathrm{~mm}$; length of pronotum $1.9 \mathrm{~mm}$; length of elytra $2.5 \mathrm{~mm}$; length of metatibia $1.9 \mathrm{~mm}$. Habitus as in Fig. 39. Coloration: body black; legs black with tarsomeres I blackish brown and tarsomeres II-V yellowish-brown to yellowish; antennae black.

Head (Fig. 40) strongly transverse; dorsal surface rather flat, with coarse, dense, and partly confluent punctation; interstices with distinct microsculpture; vertex delimited from posterior portion of head (neck) by a deep transverse sulcus. Antenna moderately long; antennomeres IV twice as long as broad, V nearly twice as long as broad, VIVII weakly oblong, and VIII-X approximately as long as broad.

Pronotum (Fig. 40) approximately 1.7 times as broad as long and 2.1 times as broad as head, of distinctive shape, broadest at posterior fourth, strongly tapering anteriad; disc strongly convex in cross-section, near posterior angles flattened; posterior angles sharply marked and directed posteriad; lateral margins narrowly separated in anterior half, gradually becoming broader in posterior half; punctation conspicuously coarse, very dense in antero-median portion, slightly less dense in lateral portions, and somewhat irregularly distributed (with impunctate patches) in posterior portion; interstices with distinct microsculpture.

Elytra conspicuously short, 1.3 times as long as pronotum and leaving tergites V-VIII and most of tergite IV unconcealed; posterior margins strongly obliquely convex; each elytron with eight distinctly punctate striae; intervals moderately flat, without microsculpture, 
with few scattered macropunctures and with extremely fine micropunctation visible only at high magnification. Scutellum weakly transverse and with transverse microsculpture. Legs rather short and stout; protarsomeres I-IV moderately dilated.

Abdomen (Fig. 41) with distinct microsculpture and with rather dense and moderately coarse punctation; tergite IV with a pair of large tomentose patches.

$\mathrm{o}^{\top}$ : tergite VIII strongly convex posteriorly; aedeagus (Figs 42-43) $1.75 \mathrm{~mm}$ long; median lobe very slender, gradually tapering apicad, and apically acute in ventral view; apical portion of ventral process straight in lateral view; parameres long and slender, extending beyond apex of median lobe and strongly curved ventrad apically, slightly asymmetric: left paramere apically obliquely truncate, right paramere apically convex, slightly longer than left paramere.

Comparative notes: This highly distinctive species differs from all its congeners by the short elytra, the punctation of the pronotum, and by the morphology of the aedeagus, particularly the asymmetric apices of the parameres. Regarding the shape of the pronotum, A.curtipennis resembles A. birmanica JANsson, 1947 (Myanmar) and A. sikkimi Fauvel, 1895 (North India: Darjeeling). Aside from its much shorter elytra, the new species differs from them as follows:

from A. birmanica by much denser punctation of the pronotum, the shape of the posterior margin of the pronotum (A. birmanica: posterior margin near the posterior angles with a distinct tooth-like process on either side) and by a smaller aedeagus (A. birmanica: length of aedeagus $1.85 \mathrm{~mm}$ );

from A. sikkimi by the coloration (A. sikkimi: apical antennomeres yellowish; lateral margins, elytra, and legs dark-brown) and by the shape of the pronotum in cross-section (A. sikkimi: disc not smoothly convex, but strongly elevated and in the middle nearly flat).

Distribution and natural history: The type locality is situated in the Gaoligong Shan in Northwest Yunnan. The holotype was sifted from litter and dead wood in a forest remnant at an altitude of $2000 \mathrm{~m}$.

\section{Acknowledgements}

I am indebted to the colleagues listed in the material section for the loan of material from the collections under their care. Benedikt Feldmann (Münster) and Harald Schillhammer (Vienna) proof-read and reviewed the manuscript.

\section{References}

Assing, V. 2014: A revision of Pronomaea ERICHSON. II. A new species from China and additional records (Coleoptera: Staphylinidae: Aleocharinae). - Linzer Biologische Beiträge 46 (2): 1211-1216. - https:// www.zobodat.at/pdf/LBB_0046_2_1211-1216.pdf.

CAmeron, M. 1930: The fauna of British India including Ceylon and Burma. Coleoptera, Staphylinidae. Vol. 1. - Taylor and Francis, London: xvii + 1-471.

Fauvel, A. 1895: Staphylinides nouveaux de l'Inde et de la Malaisie. - Revue d'Entomologie 14: 180-286.

FAuvel, A. 1904: Staphylinides exotiques nouveaux. $2^{\mathrm{e}}$ Partie. - Revue d'Entomologie 23: 76-112.

Herman, L. H. 2001: Catalog of the Staphylinidae (Insecta: Coleoptera). 1758 to the end of the second millennium. Volumes I-VII. - Bulletin of the American Museum of Natural History 265: 4218 pp.

JANsson, A. 1947: Entomological results from the Swedish expedition 1934 to Burma and British India. Coleoptera: Staphylinidae (p. p.) et Silphidae (p. p.). Collected by René Malaise. - Arkiv för Zoologi 38A (19): 1-18.

LEWIS, G. 1893: Note XXXIII. On a new species of Apatetica (Staphylinidae). - Notes from the Leyden Museum 15: 248-249.

Schülke, M. \& Smetana, A. 2015: Staphylinidae, pp. 304-1134. - In: LöвL, I. \& LöвL, D. (eds), Catalogue of Palaearctic Coleoptera. Volume 2. Hydrophiloidea - Staphylinoidea. Revised and updated edition. - Brill, Leiden: xxvi + 1702 pp. 